\title{
Modified activated carbon and bentonite used to adsorb petroleum hydrocarbons emulsified in aqueous solution
}

\author{
Eman Abdelwahab Emam \\ Department of Petroleum Refining Eng. and Petrochemicals, Faculty of Petroleum and Mining Eng., Suez University, Suez, Egypt
}

Email address:

emamtah@yahoo.com

\section{To cite this article:}

Eman Abdelwahab Emam. Modified Activated Carbon and Bentonite Used to Adsorb Petroleum Hydrocarbons Emulsified in Aqueous Solution. American Journal of Environmental Protection. Vol. 2, No. 6, 2013, pp. 161-169. doi: 10.11648/j.ajep.20130206.17

\begin{abstract}
Adsorption is one commonly used technique for treatment of petroleum contaminated water. This study aims to modify the adsorption surface of bentonite clay and activated carbon as organoclay and acid modified activated carbon, respectively. The modified and unmodified adsorbents were characterized by analysis of specific surface area, cation exchange capacity and point of zero charge $\left(\mathrm{pH}_{\mathrm{pzc}}\right)$. Furthermore, adsorbents efficiencies were evaluated in the adsorption of petroleum hydrocarbon from oil-water emulsion. The synthetic wastewater samples were generated by emulsifying diesel oil in distilled water to investigate the effects of: (i) contact time, (ii) initial hydrocarbon concentration, (iii) $\mathrm{pH}$, and (iv) adsorption isotherm. The modification of bentonite and activated carbon produced higher adsorption capacity than the unmodified adsorbents. In addition, the results showed that the adsorption of hydrocarbon depend strongly on $\mathrm{pH}$ and increased with increasing contact time and the equilibrium was reached after 3 and $4 \mathrm{hr}$ with clays and activated carbons, respectively. The hydrocarbon removal efficiency achieved in the following order: organic bentonite $>$ acid modified activated carbon $>$ bentonite $>$ activated carbon. The modified bentonite is an excellent alternative in the adsorption of hydrocarbon from oil-water emulsion removal with the highest adsorption capacity ( $48 \mathrm{mg} / \mathrm{g}$ at $2 \mathrm{~g} / \mathrm{L})$. Freundlich isotherm was best to describe the adsorption isotherm of hydrocarbons from oil-water emulsion by the all adsorbents.
\end{abstract}

Keywords: Petroleum Hydrocarbon, Oil-Water Emulsion, Adsorption, Bentonite, Acid Modified Activated Carbon, Organoclay

\section{Introduction}

Petroleum industry is among major users of water, and produces a large volume of wastewater, varying in composition and pollutant concentration, including hydrocarbon containing wastewater. Hydrocarbons mean oil, grease, crude petroleum, tars, vegetable and mineral oils, animal fats, light and heavy fuel, as well as their mixtures, which are insoluble or poorly soluble in water. Hydrocarbon-containing water has two distinct components, a gravity separable phase and an emulsified phase. Hydrocarbons are present as "free oil" (hydrocarbons that separate from wastewater and float to the liquid surface) and as "emulsified oil" (hydrocarbons that remaining stable suspension and do not separate from the wastewater). The emulsified wastewater undergoes incomplete microbial degradation [1] when discharged without treatment, and not only degrades water quality but is also toxic to human and marine life and environment [2]. Therefore the removal of hydrocarbon from oil-water emulsion has a great importance for the environment $[3,4]$.

Many techniques are available for the removal of hydrocarbon from oil-water emulsion. These techniques include the use of a variety of filters [5], chemical dosing [6], gravity separation [7], biological processes [8,9] and air flotation [10]. However, these techniques are ineffective in removing smaller oil droplets of emulsions, particularly in stable emulsions and when hydrocarbon concentration is low. Moreover, membranes are the most effective for oil emulsion separation from water [1], however, fouling of these membranes is frequent [11]. Adsorption onto low-cost materials is one technique used largely for removing organics dissolved in water.

\subsection{Adsorption}

Adsorption is a separation process in which gas or liquid molecules are adsorbed on the surface of an adsorption solid. There is a variety of adsorbents. The most common are activated carbon (AC), clay, silica, alumina and zeolite. $\mathrm{AC}$ is an effective adsorbent, has a high surface area, an 
extensively developed pore structure, a high crystalline form and mechanical strength [12]. In addition, AC possesses good porous texture allowing the high adsorption capacity in the removal of a wide variety of organic compounds including oil from water and has proven to be technically feasible [12-14]. Removal of petroleum hydrocarbon polluted ground-water using of AC was investigated, and it was recommended that powder activated carbon is more effective in the treatment of ground water than granular activated carbon [13].

The surface chemistry of carbon materials is basically determined by the acidic and basic character of their surface, and can be changed by modifying them with oxidizing agents either in the gas phase or in solution [15]. Many methods of modifying the AC surface have been introduced using chemical/physical treatment [16], impregnation [17] and surface modification with surfactant [15]. It has also been shown that chemical modifications can improve the adsorption capabilities of activated carbons for various molecules [15-17]. Modification of the surface chemistry of activated carbons may be a possible attractive route toward novel applications of these materials as an adsorbent for contaminants removal.

Clays are very important minerals as a result of their surface properties and the fact that they are reactive hence making them very important in many industrial applications and environmental control [14]. They are mainly composed of layers (sheet-like structures) and are therefore referred to as phyllosilicate minerals. Organically modified clays are proposed as a good option for removal of oil from produced water [2-4,18]. Some studies have showed that replacing the inorganic exchange cations of clay minerals with organic cations can result in greatly enhanced capacity of the materials to remove organic contaminants $[2,18]$.

The adsorption for some organic pollutants using bentonite organoclay has been studied $[14,18]$. It was reported that bentonite organoclay is effective in the removal of hydrocarbon from oily waters. In filtration (column) systems, a mixture of organoclay and anthracite can remove as much as $50 \%$ of its weight in oil which is about 5 - 7 times the removal rate of activated carbon [14]. Another study had also shown that bentonite organoclay/anthracite were quite effective in removing oil from a number of oil-water emulsions [19].

\subsection{Adsorption Isotherm}

The adsorption isotherm indicates whether molecules can be removed by adsorption and describe the distribution of molecules to be adsorbed between the adsorbent and the solution. They also give approximate values of adsorption capacities at realistic operating conditions. Furthermore, they can be used to assess the approximate consumption of adsorbent as well as the cost of the installation. Langmuir and Freundlich isotherms are used for fitting the experimental data in adsorption studies to understand the extent and degree of favourability of adsorption. The
Freundlich isotherm is defined as an empirical model representing the equilibrium between adsorbate and adsorbent. The Langmuir isotherm is a mathematical model derived from theoretical considerations. These isotherms have constants in their general form given by equations 1 and 2 , respectively [20].

$$
\begin{aligned}
& q_{e}=\left(a b C_{e}\right) /\left(1+b C_{e}\right) \\
& q_{e}=k C_{e}^{1 / n}
\end{aligned}
$$

These models are rearranged to the linear form as follows:

$$
\begin{gathered}
\frac{1}{q_{e}}=\frac{1}{a}+\frac{1}{a b C_{e}} \\
\log \left(q_{e}\right)=\log (k)+\left(\frac{1}{n}\right) \log \left(C_{e}\right)
\end{gathered}
$$

where $q_{e}$ is the amount of adsorbed adsorbate per unit weight of adsorbent $(\mathrm{mg} / \mathrm{g}), C_{e}$ is the concentration of adsorbate in the liquid $(\mathrm{mg} / \mathrm{L}), k, n$ are the constants specific to test conditions and the carbon type (Freundlich constants) and $a, b$ are the capacity and energy of adsorption (Langmuir constants).

The constants $a$ and $k$ indicate the affinities for adsorption. The slope $(1 / n)$ indicates the effects of concentration on adsorption capacity and for most organics $(1 / n)<1$. A larger value of $\mathrm{k}$ indicates a higher rate of adsorbate removal [14]. It should be noted that the isotherm constants are important in understanding the adsorption mechanism and their subsequent application for predicting some important design parameters.

The essential characteristics of the Langmuir isotherm could be examined by an adsorption dimensionless constant, separation factor or equilibrium parameter $r$ that was calculated by following equation [21]:

$$
r=\frac{1}{1+b C_{0}}
$$

where $b$ is the Langmuir constant related to the energy of adsorption $(\mathrm{L} / \mathrm{mg})$ and $C_{0}$ is the initial adsorbate concentration $(\mathrm{mg} / \mathrm{L})$ and these values were derived from Langmuir isotherm. The character of the adsorption isotherm was related to the value of $r$. The adsorption is unfavorable $(r>1)$, linear $(r=1)$, favorable $(0<r<1)$, or irreversible $(r=0)$.

The main objective of this study is to investigate the efficiencies of the modification surfaces of bentonite and activated carbon for the removal of petroleum hydrocarbon from oil emulsified water. The organic bentonite and acid activated carbon were synthesized by using cetyltrimethyl ammonium chloride (CTAC) and nitric acid on the bentonite and activated carbon, respectively. The unmodified and modified adsorbents were characterized by the determination of specific surface area, cation exchange 
capacity and point of zero charge. Adsorption capacities of the all adsorbents were investigated with various operating parameters such as contact time, initial hydrocarbon concentration, $\mathrm{pH}$ value has been investigated. Langmuir and Freundlich isotherm equations were employed to quantify the adsorption equilibrium.

\section{Experimental}

\subsection{Hydrocarbon-Water Emulsion}

The dispersed petroleum hydrocarbon phase used was diesel oil supplied by Suez Company, which has an approximated specific gravity of 0.84 at $25{ }^{\circ} \mathrm{C}$. Distilled water and commercial surfactant Triton ${ }^{\circledR} \mathrm{X}-100$ (supplied by Lobachemie, India) were used. The hydrocarbonemulsion in water was prepared by mixing Triton ${ }^{\circledR} \mathrm{X}-100$ with water first for 10 minutes then dispersed the hydrocarbon phase into the water to give the desired concentration of hydrocarbon. The solution was then mixed at $25^{\circ} \mathrm{C}$ in a beaker at high stirring rate for one hour to ensure uniform droplet size.

\subsection{Activated Carbon}

A commercial activated carbon from NORIT Nederland B.V. type NRS CARBON EA 0.5-1.5 was used and is abbreviated as NRS. The characterisations of the NRS are $350 \mathrm{~kg} / \mathrm{m}^{3}$ apparent density, $13 \mathrm{wt} \%$ ash content, $10 \mathrm{wt} \%$ moisture content (as packed) and min. 850 iodine number. All analyses are based on NORIT Standard Test Methods (NSTM). The NRS was used with and without modification.

Chemical modification with nitric acid was used to enhance the adsorption capacity of the NRS. To this purpose a certain amount of NRS was washed several times with distilled water. NRS was dried in an oven at $105{ }^{\circ} \mathrm{C}$ overnight and then soaked in $1 \mathrm{M}$ nitric acid solution for 24 hr with constant shaking in an orbital shaker at a constant temperature of $25{ }^{\circ} \mathrm{C}$. During this time the ratio of solution to NRS was fixed to $1 \mathrm{~L}$ per $5 \mathrm{~g}$. Subsequently the acid solution was removed and the NRS was washed several times with distilled water, decanted and dried overnight at $105{ }^{\circ}$ Cand then stored in a vacuum desiccator. The acidic modified NRS is abbreviated as NA-NRS.

\subsection{Bentonite Clay}

Bentonite clay was supplied from the Sphinx Milling Station Company (Alexandria free zone, Egypt). Natural bentonite has low alumina content and contains high silica contents and its chemical composition (\%): $\mathrm{SiO}_{2}=55.12$, $\mathrm{Al}_{2} \mathrm{O}_{3}=16.14, \mathrm{Fe}_{2} \mathrm{O}_{3}=8.25, \mathrm{CaO}=1.17, \mathrm{MgO}=2.86$, $\mathrm{Na}_{2} \mathrm{O}=1.41, \mathrm{~K}_{2} \mathrm{O}=1.05$ and $\mathrm{TiO}_{2}=1.18$. The analysis was made in Central Metallurgical Research Institute in Alexandria. To produce organic bentonite clay (orgbentonite), the surfactant used was cetyltrimethyl ammonium chloride (CTAC), purchased from SigmaAldrich. Initially, a dispersion of bentonite (4 wt \%) in distilled water was prepared under agitation for $3 \mathrm{hr}$. A pre- dissolved equivalent amount of surfactant (according to the cation exchange capacity of bentonite) was slowly added to the bentonite suspension and the mixture was stirred for a further $24 \mathrm{hr}$. A product organoclay (org-bentonite) was washed several times with distilled water to remove excess surfactants, filtered and dried in an oven at $50-60{ }^{\circ} \mathrm{C}$ for 48 hours, crushed and sieved, and then stored in a vacuum desiccator.

\subsection{Characterizations of the Adsorbents}

The specific surface area and cation exchange capacity (CEC) of the unmodified and modified adsorbents were determined using Sears' method [22], and the ammonium acetate method [23], respectively. A potentiometric titration method [24] was used to determine the $\mathrm{pH}$ of point of zero charge $\left(\mathrm{pH}_{\mathrm{pzc}}\right)$.

\subsection{Adsorption Procedure}

All experiments were carried out at ambient temperature in batch mode. Prior to each experiment a predetermined amount of adsorbent was added to a conical flask and filled with a $200 \mathrm{ml}$ of hydrocarbon-water emulsion having the desired $\mathrm{pH}$ and stirred with constant agitation (200 rpm) using an orbital shaker. The desired initial $\mathrm{pH}$ was adjusted adding a $\mathrm{NaOH}$ or $\mathrm{H}_{2} \mathrm{SO}_{4}$ solution. The flask containing the sample was withdrawn from the shaker at a set time interval. The samples were filtered through filter papers (Whatman No. 3). The experiments were carried out under different experimental conditions such as contact time, $\mathrm{pH}$, initial concentration of hydrocarbon and adsorption isotherm. The amount of hydrocarbon removed was determined.

\subsection{Hydrocarbon Analysis}

The total hydrocarbon content was measured according to the standard method ASTM-D 3921. The samples were acidified to a $\mathrm{pH}<2$ by adding concentrated $\mathrm{H}_{2} \mathrm{SO}_{4}$. Hydrocarbons were extracted for $1 \mathrm{~min}$ by vigorous shaking with the same volume of 1,1,2trichlorotrifluoroethane. Thereafter, the hydrocarboncontaining solvent layer was separated, eluted through a column containing $\mathrm{Al}_{2} \mathrm{O}_{3}$ and dehydrated with $\mathrm{Na}_{2} \mathrm{SO}_{4}$. The extracted hydrocarbons were measured by infrared spectroscopy (OCMA-220 HORIBA).

\section{Results and Discussion}

Adsorption has been widely studied as an effective technique for removing organic contaminated water. The removal efficiency is influenced by various factors such as adsorbent types, adsorbent modifications, initial organic concentration and $\mathrm{pH}$ value. Batch mode adsorption experiments are described aimed at obtaining the optimum conditions for removal of the petroleum hydrocarbon from oil-water emulsion. The characteristics of the unmodified and modified adsorbents such as specific surface area, 
cation exchange capacity and point of zero charge were determined.

\subsection{Characteristics of Adsorbents}

The characteristics of NRS, NA-NRS, bentonite and orgbentonite differed (Table 1). The specific surface area of NA-NRS was about $13.7 \%$ lower than that of NRS, which indicates that $\mathrm{HNO}_{3}$ modification decrease the specific surface area of the activated carbon. This could arise from pore blockage by adsorbed nitric acid molecules. Because of its small molecular size, nitric acid can easily access the pore structure of the activated carbon. The CEC value of NA-NRS (1.42 meq/g) was 2 times higher than that of NRS. The difference indicates that the nitric acid might introduce acidic surface oxides on the carbon surface which caused formation of a large number of oxygen-containing functional groups. It was also reported that modification of activated carbon with $\mathrm{HNO}_{3}$ increased the quantity of acidic functional groups on activated carbon surface as oxygen groups and structures containing $\mathrm{N}-\mathrm{O}$ bonds that change the surface chemistry and can alter the surface area and porosity of the original activated carbon [15]. The number of acidic functional groups is closely related to the capacity of activated carbon to adsorb hydrocarbon compounds; thus NA-NRS should have a greater affinity for hydrocarbon compounds than NRS.

Table 1. Characteristics of unmodified and modified adsorbents

\begin{tabular}{lllll}
\hline Parameter & NRS & $\begin{array}{l}\text { NA- } \\
\text { NRS }\end{array}$ & bentonite & $\begin{array}{l}\text { org- } \\
\text { bentonite }\end{array}$ \\
\hline $\begin{array}{l}\text { Specific surface } \\
\text { area, } \mathrm{m}^{2} / \mathrm{g}\end{array}$ & 877 & 756.8 & 27.1 & 8.7 \\
$\mathrm{CEC}, \mathrm{meq} / \mathrm{g}$ & 0.687 & 1.42 & 0.753 & 0.41 \\
$\mathrm{pH}_{\mathrm{pzc}}$ & 7.85 & 6.4 & 7.73 & 6.67 \\
\hline
\end{tabular}

The CEC of org-bentonite was $0.41 \mathrm{meq} / \mathrm{g}$ lower than that of bentonite $(0.753 \mathrm{meq} / \mathrm{g})$. This result was expected as a result of an ion exchange with the quaternary ammonium group (CTAC) of the modified bentonite. The CTAC modification has also decreased the specific surface area of the org-bentonite (Table 1). However, this result was unexpected since modification of the clay should ideally increase the basal spacing of the clay interlayer which implies more adsorption sites are accessible. One possible reason for the observed reduction in the surface area of orgbentonite may relate to introduce the large surfactant molecules in the clay interlayer. Depending on the type of the surfactants, the internal pore spaces may be predominantly occupied by long-chained surfactants. This may lead to a decrease in the specific surface area of orgbentonite compared with the clay starting material (bentonite). This suggests that adsorption is mainly occurring on the external surface of the org-bentonite, hence the corresponding low surface area obtained.

Surface charge in the aqueous systems depends on activities of potential-determining ions $\left(\mathrm{H}+\right.$ and $\left.\mathrm{OH}^{-}\right)$and electrolyte concentrations. Depending on suspension $\mathrm{pH}$, the adsorbent surfaces can bear net negative, or positive, or no charge. The $\mathrm{pH}$ where the net total particle charge is zero is called the point of zero charge $\left(\mathrm{pH}_{\mathrm{pzc}}\right)$, which is one of the most important parameters used to describe variable charge surfaces. If the $\mathrm{pH}$ of a suspension is above its $\mathrm{pH}_{\mathrm{pzc}}$ the suspension surface will have a net negative charge and predominantly exhibit an ability to exchange cations (one positive ion by another), while the suspension will mainly retain anions (electrostatically) if its $\mathrm{pH}$ is below its $\mathrm{pH}_{\mathrm{pzc}}$ (one negative ion for another). In suspension, researchers have generally relied on potentiometric titration, which assesses changes in surface potential with changes in the activities of $\mathrm{H}^{+}$and $\mathrm{OH}^{-}$, to determine the point of zero $\left(\mathrm{pH}_{\mathrm{pzc}}\right)$.

The effect of the modification was investigated by potentiometric titration of the activated carbon and bentonite before and after modification. The potentiometric titration data were used in the determination of the point of zero charge $\left(\mathrm{pH}_{\mathrm{pzc}}\right)$. According to modify the surface potential with changes in the activities of $\mathrm{H}^{+}$and $\mathrm{OH}^{-}$, the $\mathrm{pH}_{\mathrm{pzc}}$ values of NRS and NA-NRS are 7.85 and 6.4, respectively (Table 1). At $\mathrm{pH}$ more or less $\mathrm{pH}_{\mathrm{pzc}}$, the surface charge of activated carbon is negative or positive, respectively.

Similar behavior was found at $\mathrm{pH}_{\mathrm{pzc}}$ value from 7.73 to 6.67 for bentonite and org-bentonite, respectively. The $\mathrm{pH}_{\mathrm{pzc}}$ was affected by original bentonite, but most affected by CTAC modification. The probable reason for this difference was attributed to the introduced quaternary ammonium group of the modified bentonite with negative surface charge.

\subsection{Effect of Contact Time}

In order to establish the equilibrium time for maximum adsorption of hydrocarbon from oil-water emulsion, the petroleum hydrocarbon adsorbed on the adsorbents (bentonite, org-bentonite, NRS, NA-NRS) were studied as a function of contact time, which varied from 0.5 to $10 \mathrm{hr}$. The study was carried out with $2 \mathrm{~g}$ adsorbent/L using initial hydrocarbon concentration of $100 \mathrm{mg} / \mathrm{L}$ at an initial $\mathrm{pH}=7$. The relationship between the amounts of hydrocarbon adsorbed per gram of adsorbent $q_{e}$ as a function of the contact time was reported in Table 2. Also, Fig. 1 shows the results of the hydrocarbon removal as a function of contact time. It was observed that the adsorption of hydrocarbon increased with increasing contact time. However, the removal of hydrocarbons by adsorption process on clays and activated carbons reached equilibrium in the first period of the process after $3 \mathrm{hr}$ and $4 \mathrm{hr}$, respectively. The adsorption process is rapid at the beginning of the process due to the adsorption of hydrocarbon onto the surface sites of adsorbents. With increasing contact time no dramatically enhancement was observed. It is obvious that in the field of economical consideration this prolonged time is not practical or suitable.

The adsorption capacity of the org-bentonite is higher 
than the AN-NRS. Also, the same trend is between bentonite and NRS. It may be attributed to that hydrocarbon droplets are usually larger than the pores of activated carbon, the carbon is quickly blinded by oil droplets resulting in plug or fill the pores. Hydrocarbon adsorption capacities of about 48, 38.5, 42 and $30 \mathrm{mg} / \mathrm{g}$ were observed during the first $4 \mathrm{hr}$ with org-bentonite, bentonite, NA-NRS and NRS, respectively (Table 2).

Table 2. Effect of contact time and initial pH on the hydrocarbon adsorbed per unit weight of adsorbent

\begin{tabular}{|c|c|c|c|c|}
\hline \multirow{2}{*}{$\begin{array}{l}\text { Contact } \\
\text { time, hr }\end{array}$} & \multicolumn{4}{|c|}{$q_{e}, \mathrm{mg} / \mathrm{g}$} \\
\hline & NRS & NA-NRS & bentonite & $\begin{array}{c}\text { org- } \\
\text { bentonite }\end{array}$ \\
\hline 0 & 0 & 0 & 0 & 0 \\
\hline 0.25 & 12.5 & 21.75 & 18 & 20 \\
\hline 0.5 & 16.5 & 27.5 & 25 & 31.5 \\
\hline 1 & 21.5 & 32.2 & 30 & 38.5 \\
\hline 1.5 & 24.5 & 35 & 32 & 42 \\
\hline 2 & 27 & 37.5 & 35 & 45 \\
\hline 3 & 28.5 & 40.75 & 38.3 & 47.85 \\
\hline 4 & 30 & 42 & 38.5 & 48 \\
\hline 6 & 29.5 & 42.5 & 39.5 & 48.2 \\
\hline 8 & 30.85 & 43.25 & 39.25 & 48.9 \\
\hline 10 & 31 & 43.5 & 39.5 & 49 \\
\hline pH & & & & \\
\hline 2.5 & 30.5 & 25 & 20 & 35 \\
\hline 5 & 29.5 & 32.5 & 27.5 & 40.5 \\
\hline 7 & 30 & 42 & 38.5 & 48 \\
\hline 9 & 29.75 & 40.5 & 39.5 & 49.9 \\
\hline 11 & 30.5 & 38.5 & 40.5 & 48.5 \\
\hline
\end{tabular}

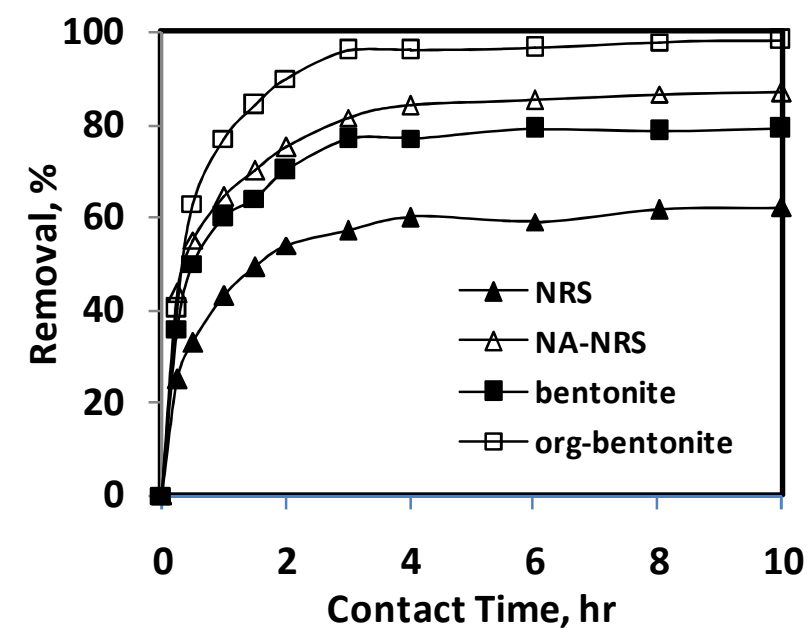

Figure 1. Effect of the contact time on the adsorption of hydrocarbon from oil-water emulsion
As shown in Fig. 1, the hydrocarbon adsorption capacity using NA-NRS is higher than NRS with all different contact time. This difference of adsorption capacity indicates that the $\mathrm{HNO}_{3}$ modification caused formation of a large number of oxygen- and nitrogen-containing functional groups and having large amounts of the surface acidic groups which can exchange their active sites with the hydrocarbon compounds present in aqueous solution. The number of acidic functional groups is closely related to the capacity of activated carbon to adsorb hydrocarbon compounds; as a result NA-NRS accessible higher adsorption capacity for hydrocarbons than NRS.

The highest adsorption capacity of org-bentonite modified by CTAC $(48 \mathrm{mg} / \mathrm{g})$ may be attributed to the change of the surface properties from hydrophilic to hydrophobic character. This is an indication of the intercalation of the ammonium quaternary cation of the surfactant in the clays. Similar results were obtained by Oliveira et al. [3] for the clay treated with CTAC. It can be concluded that org-bentonite is more appropriate materials for the removal of hydrocarbon from oil-water emulsions.

\subsection{Effect of $\mathrm{pH}$}

$\mathrm{pH}$ is one of the most important parameters while assessing the adsorption capacity from aqueous solution. The $\mathrm{pH}$ of the system controls the adsorption capacity due to its influence on the surface properties of the adsorbent. Therefore, adsorption from solution can be highly $\mathrm{pH}$ dependent. The influence of $\mathrm{pH}$ in the range of 2.5 - 11 was studied keeping all other parameters constant (hydrocarbon concentration $=100 \mathrm{mg} / \mathrm{l}$; contact time $=4 \mathrm{hr}$, adsorbent dosage $=2 \mathrm{~g} / \mathrm{L}$ ). The $\mathrm{pH}$ dependence of amounts of hydrocarbon adsorbed per gram of adsorbent $\mathrm{q}_{\mathrm{e}}$ onto the unmodified and modified adsorbentsare reported in Table 2. The experiments carried out using NRS show that there was no significant change in the removal of hydrocarbon over the entire $\mathrm{pH}$ range (Figure 2).

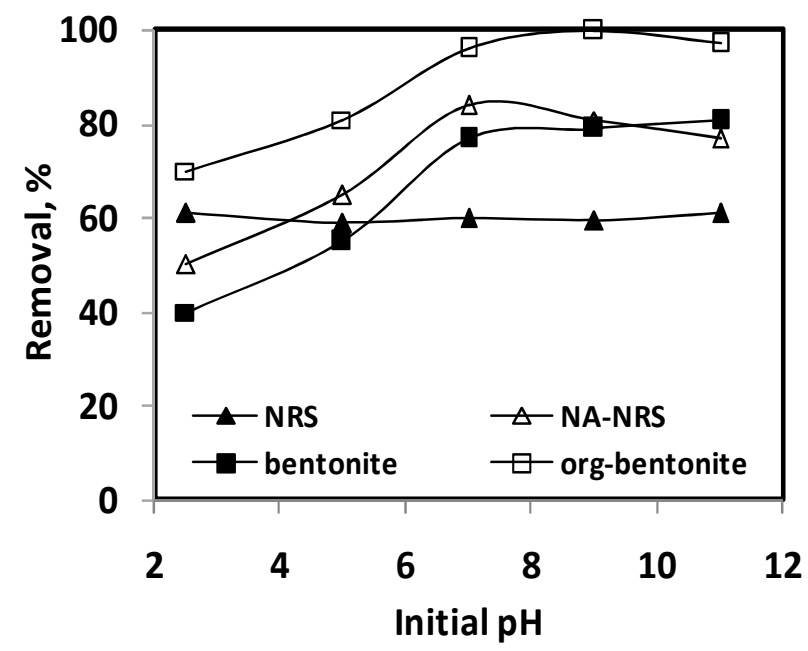

Figure 2. Effect of $\mathrm{pH}$ on the adsorption of hydrocarbon from oil-water emulsion 
This result indicates that neither $\mathrm{H}^{+}$nor $\mathrm{OH}^{-}$ions could influence the adsorption capacity of the hydrocarbon compounds using NRS. In other words, the adsorption of hydrocarbon compounds on NRS does not involve an ionexchange mechanism. However, it strongly affected its removal when the modified carbon (NA-NRS) was applied. The hydrocarbon removal increased with increasing $\mathrm{pH}$ using NA-NRS. The highest adsorption capacity was achieved at $\mathrm{pH}=7$ by NA-NRS (42 $\mathrm{mg} / \mathrm{g})$ and it slightly deceased with increasing the $\mathrm{pH}$ up to 11 . The increase of the hydrocarbon adsorption capacity with increasing $\mathrm{pH}$ is due to the fact that the surface functional groups of the oxidized carbons (AN-NRS) ionize leading to greater retentive power towards the hydrocarbon compounds.

Both bentonite and org-bentonite showed similar behaviour at low $\mathrm{pH}$ (lower than $\mathrm{pH}$ 7), although hydrocarbon removal with org-bentonite is considerably higher than unmodified bentonite. The hydrocarbon removal with org-bentonite increased with increasing $\mathrm{pH}$ and reached a plateau of maximum value $(99.8 \%)$ when the initial $\mathrm{pH}$ was 8 . However, the adsorption of hydrocarbon increased for bentonite with increasing $\mathrm{pH}$ from 2.5 to $\mathrm{pH} 7$ (40\% to $77 \%$, respectively) afterthought slightly increased with increasing $\mathrm{pH}$ to $11(80.5 \%)$. It can be seen that the surface charge of bentonite is a strong function of the $\mathrm{pH}$. The better adsorption ability of orgbentonite may be related to that the quaternary ammonium was attached to the clay surface and partially neutralized the negative charge of the bentonite. The org-bentonite was less negative charged and becomes hydrophobic in character due to the surfactant exchange than bentonite. The less negative charged surface reduced the repulsion between org-bentonite and hydrocarbon compounds which are beneficial to the hydrocarbon adsorption on the orgbentonite surface through hydrophobic bonding between hydrocarbon molecules in oil-emulsion water and alkyl chain of CTAC. It is because the long chain alkyl $\left[\mathrm{CH}_{3}\left(\mathrm{CH}_{2}\right)_{15} \mathrm{~N}(\mathrm{Cl})\left(\mathrm{CH}_{3}\right)_{3}\right]$ of the quaternary ammonium may provide a more hydrocarbon compounds adsorption surface to improve the performance of the org-bentonite. In this case, hydrocarbon compounds can be intercepted by long liner alkyl chain much more easily, which is beneficial to make adsorption occur smoothly.

\subsection{Effect of Initial Hydrocarbon Concentration}

Figure 3 summarises the effect of the initial hydrocarbon concentration in the range of $25-400 \mathrm{mg} / \mathrm{L}$ on hydrocarbon adsorption from oil-water emulsion by unmodified and modified adsorbents at a adsorbent dosage of $2 \mathrm{~g} / \mathrm{L}, \mathrm{pH}=7$ and a contact time of $4 \mathrm{hr}$. The results showed that the same trend of all adsorbents that, the adsorption of hydrocarbon decrease with increasing the concentration of adsorbate. The hydrocarbon removal rate of all adsorbents are variable for about $75-51 \%, 85-65 \%$, $90-67 \%$ and $99.3-74.5 \%$ by NRS, bentonite, AN-NRS and org-bentonite, respectively.

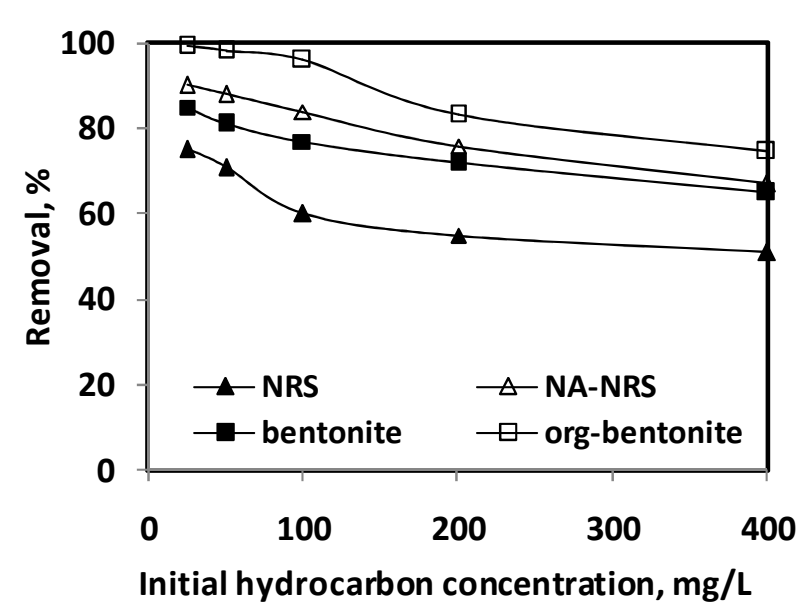

Figure 3. Effect of initial hydrocarbon concentration on the adsorption of hydrocarbon from oil-water emulsion

These results were expected and the explanation of these results is that the adsorption of different concentration of hydrocarbon onto the constant adsorption sites of adsorbent and at a constant time of adsorption. However, at low concentration of hydrocarbon, the ratio between the hydrocarbon compounds and the adsorption sites is nearly similar. At a high concentration of hydrocarbon the ratio between hydrocarbon compounds and the adsorption sites tend to increase. Accordingly, the number of free adsorption sites tends to decease, under this condition the removed amount of hydrocarbon tends to decease. Furthermore, one can realize from the data in Figure 3 that org-bentonite is more potent than other adsorbents for removal of hydrocarbon from oil-water emulsion. The explanation of these results is that CTAC modified bentonite contains a long chain alkyl which may enhance the interaction between hydrocarbon compounds and orgbentonite molecules.

\subsection{Adsorption Isotherm}

Adsorption isotherms were determined for adsorbent dosages in the range of $0.5-15 \mathrm{~g} / \mathrm{L}$ for the unmodified and modified adsorbents. The initial hydrocarbon concentration was $100 \mathrm{mg} / \mathrm{L}$ at $\mathrm{pH} 7$ and the samples were agitated for 4 hr. As shown in Fig. 4, the removal of hydrocarbon increased gradually from $26,47,38,62 \%$ up to $84,99,93$, $100 \%$ using NRS, NA-NRA, bentonite and org-bentonite, respectively. However, these results were expected since as the dose of adsorbent increases, the number of adsorbent sites increases. These amounts attach more ions to their surfaces. Similar results were reported where many types of materials were used as adsorbents [25]. However, in particular for org-bentonite where only a concentration of 8 $\mathrm{g} / \mathrm{L}$ is required, to reduce the hydrocarbon from an initial concentration of $100 \mathrm{mg} / \mathrm{L}$ to non-detectable levels. In addition, the increasing in the adsorbent dosages more than $8 \mathrm{~g} / \mathrm{L}$ with other adsorbents leads to no significant hydrocarbon removal. The explanation of these results is 
that at low dosage of adsorbent the adsorption sites are diluted in the solution and available for interaction with hydrocarbon from water whereas at high concentration of adsorbent no significant removal due to possible aggregation of adsorbent in the water. Accordingly, the availability of free adsorption sites is limited for removal of hydrocarbon. Consequently, the concentration of the adsorption site in water should be optimized.

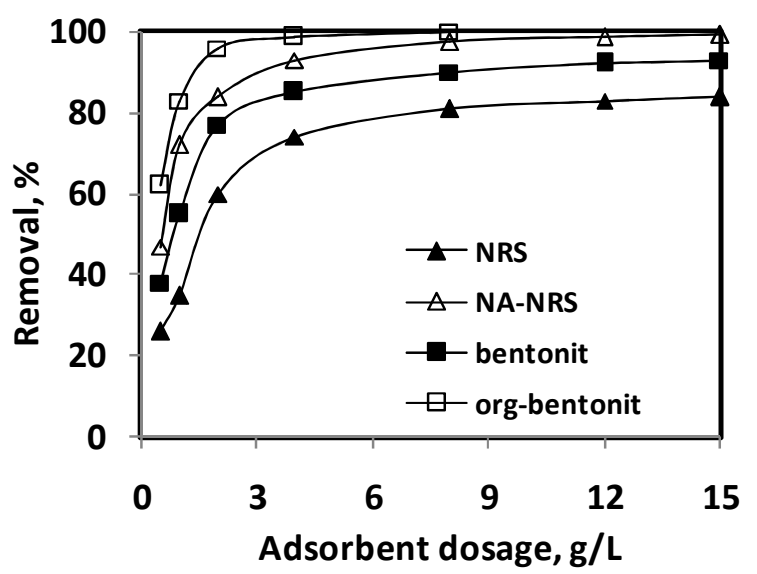

Figure 4. Effect of adsorbent dosage on the adsorption of hydrocarbon from oil-water emulsion

Adsorption isotherms for the four adsorbents were expressed using Langmuir isotherm by plotting $1 / q_{e}$ against $1 / C_{e}$ (as shown in Fig. 5) and Freundlich isotherm by plotting $\log q_{e}$ against $\log C_{e}$ (as shown in Fig. 6). The results in Figures 5 and 6 are correlated by the Langmuir and the Freundlich equations (see equations 1,2 and 5) with the resulting parameters listed in Table 3. The isotherms yield constants whose values express the affinity of adsorbate for the surface of adsorbent. For practical reasons the adsorption capacity of an adsorbent should be as high as possible. Appling the Langmuir isotherm model, it was observed that the $(a)$ value from the Langmuir isotherm was 2 times larger for NA-NRS and org-bentonite than for NRS and bentonite, respectively (Table 3). Furthermore, the values of $r$ calculated by the Eq. (5) are between 0 and 1 indicating a so-called favourable adsorption [21]. The higher values of $k$ (applying the Freundlich model) indicating more sorption, so the results show that org-bentonite offered a maximum adsorption capacity compared with other adsorbents. Also, the adsorption capacity of NA-NRS is higher than that of NRS and bentonite. In addition, $1 / n$ value for org-bentonite is 0.48 . The smaller values of $1 / n$, the higher the affinity between adsorbate and adsorbent. For bentonite and NRS (Table 3$)$ the $(1 / n)$ values are larger than 1 , indicating that the adsorption capacity of bentonite and NRS will be high at high adsorbent dosages but will rapidly diminish at lower dosages of adsorbent. It can be concluded that, the acid treatment using $\mathrm{HNO}_{3}$ is a good method to enhance the capacity of activated carbon to adsorb hydrocarbon, but the modification of bentonite with CTAC exhibited a highest capacity to adsorb hydrocarbon from oil-water emulsion.

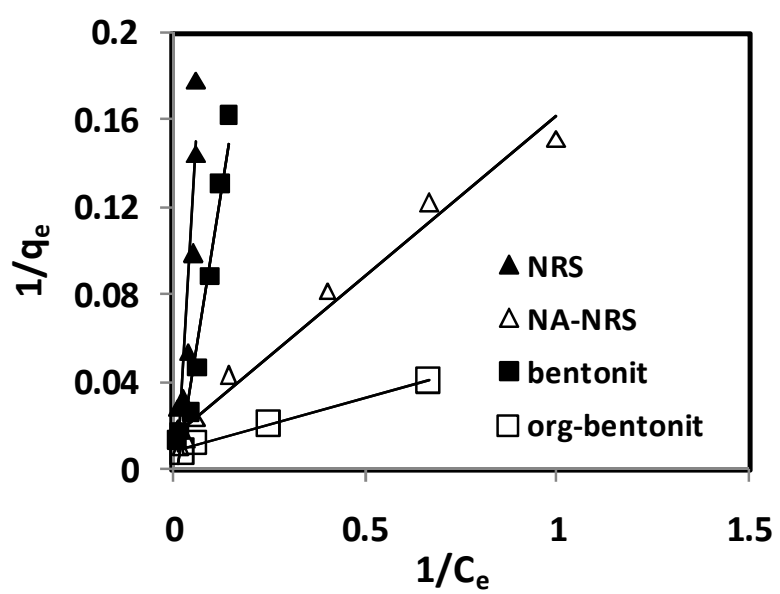

Figure 5. Langmuir isotherm adsorption of hydrocarbon from oil-water emulsion

The adsorption data obtained by Langmuir isotherms model with lower correlation coefficient $(\mathrm{R} 2=0.8949)$ using NRS while all the adsorption data analyzed by the Freundlich isotherms model conform best to following Freundlich equation with good correlation coefficients (R2 $=0.9314-0.9955)$. Hence, the Langmuir equation does not fit the experimental results very well. On the contrary, Freundlich isotherm is best to describe the adsorption of hydrocarbons from oil-water emulsion by the all adsorbents.

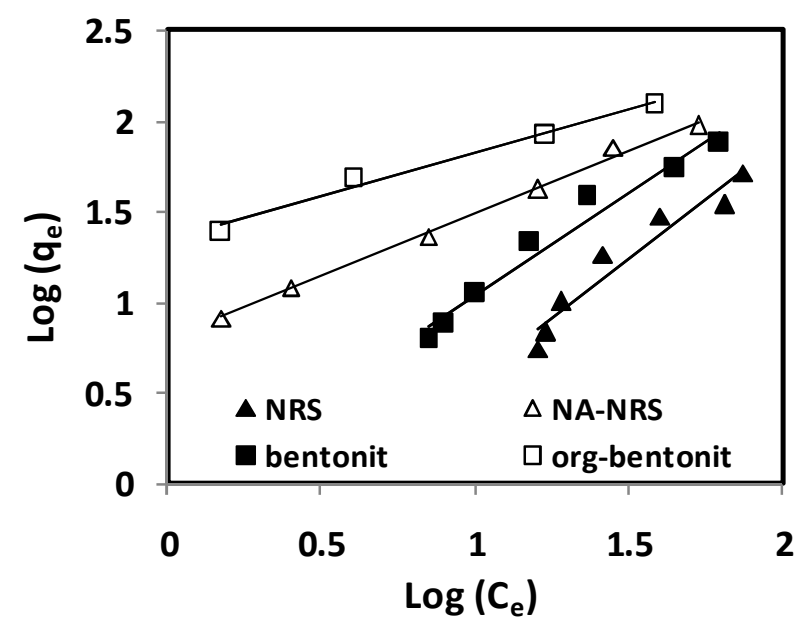

Figure 6. Freundlich isotherm adsorption of hydrocarbon from oil-water emulsion

\section{Conclusions}

The results show that the studied adsorbents can efficiently adsorbed the petroleum hydrocarbon from oilwater emulsion in water. The results of this study clearly demonstrate the importance of choosing the optimum adsorption parameters to obtain high adsorption rates of the hydrocarbon, which is essential for any practical application of adsorption process. The surface modification of bentonite and activated carbon reduced the specific surface area, $\mathrm{CEC}$ and $\mathrm{pH}_{\mathrm{pzc}}$. The adsorption capacity of the 
four adsorbents was achieved in the following order: orgbentonite $>$ NA-NRS $>$ bentonite $>$ NRS. The hydrocarbon adsorption condition depends strongly on $\mathrm{pH}$ and the initial oil concentration. The time to attain equilibrium is beyond 3 and $4 \mathrm{hr}$ using clays and activated carbons, respectively, where the hydrocarbon was removed to a non-detectable level (n.d.) with $8 \mathrm{~g} / \mathrm{L}$ of org-bentonite. The adsorption isotherms data were well fitted with the Freundlich model. It can be concluded that, the nitric acid modification is a good method to enhance the capacity of activated carbon to adsorb hydrocarbon, but the modification of bentonite with CTAC exhibited a highest adsorption capacity and can be considered as a promising adsorbent for the removal of hydrocarbon from oil-water emulsion.

Table 3. Adsorption isotherms constants for hydrocarbon removal from oil-water emulsion after 4 hr contact time

\begin{tabular}{|c|c|c|c|c|c|c|c|}
\hline \multirow{2}{*}{ Adsorbent } & \multicolumn{4}{|c|}{ Langmuir } & \multicolumn{3}{|c|}{ Freundlich } \\
\hline & $\begin{array}{c}a \\
\mathrm{mg} / \mathrm{g}\end{array}$ & $\begin{array}{c}b \\
\mathrm{~L} / \mathrm{mg} \\
\end{array}$ & $r$ & $\mathbf{R}^{2}$ & $\begin{array}{c}k \\
\mathrm{mg} / \mathrm{g}\end{array}$ & $1 / n$ & $\mathbf{R}^{2}$ \\
\hline NRS & 31.25 & 0.011 & 0.4739 & 0.8949 & 0.198 & 1.298 & 0.9314 \\
\hline NA-NRS & 65.79 & 0.104 & 0.0878 & 0.9789 & 6.246 & 0.698 & 0.9955 \\
\hline Bentonite & 63.291 & 0.137 & 0.0681 & 0.9656 & 0.801 & 1.138 & 0.9653 \\
\hline org-bentonite & 123.46 & 0.165 & 0.0571 & 0.995 & 21.863 & 0.481 & 0.9857 \\
\hline
\end{tabular}

\section{References}

[1] Espinoza-Gómez, H. and Lin, S. W.: Oil water separation, using a hydrophilic polysulfonepolyvinylpyrrolidone ultrafiltration membrane. Rev. Int. Contam. Ambient., 2004, 20 (2), 77-82.

[2] Cavalcanti, J. V. F. L.; Abreu, C. A. M.; Carvalho, M. N.; Sobrinho, M. A. M.; Benachour, M. and Baraúna, O. S.: Removal of effluent from petrochemical wastewater by adsorption using organoclay. Petrochemicals, DrVivek Patel (Ed.), ISBN 978-953-51-0411-7, 2012, 277-294.

[3] Oliveira, G. C.; Mota, M. F.; Silva, M. M.; Rodrigues, M. G. F. and Laborde, H. M.: Performance of natural sodium clay treated with ammonium salt in the separation of emulsion oil in water. Brazilian Journal of Petroleum and Gas, 2012, 6 (4), 171-183.

[4] Mowla, D.; Karimi, G. and Salehi, K.: Modeling of adsorption breakthrough behaviors of oil from salty waters in a fixed bed of commercial organoclay/sand mixture. Chemical Engineering Journal, 2013, 218, 116-125.

[5] Bansal S.; von Arnim V.; Stegmaier T. and Planck H.: Effect of fibrous filter properties on the oil-in-water-emulsion separation and filtration performance. Hazardous Materials, 2011, 190 (1-3), 45-50.

[6] Fu, Y. and Chung, D. D. L.: Coagulation of oil in water using sawdust, bentonite and calcium hydroxide to form floating sheets. Appl. Clay Sci., 2011, 53, 634-641.

[7] Berman, Y. and Tamir, A.: Kinetics of droplets' sedimentation in a continuous gravity settler. Chem. Eng. Sci., 2003, 58, 2089-2102.

[8] Bregnard, T. P.-A.; Höhener, P.; Häner, A. and Zeyer, J.: Degradation of weathered diesel fuel by microorganisms from a contaminated aquifer in aerobic and anaerobic microcosms. Environ. Toxicol. Chem., 1996, 15, 299-307.

[9] Domenico, D. M.; Giudice, A. L.; Michaud, L.; Saitta, M. and Bruni, V.: Diesel oil and PCB-degrading psychrotrophic bacteria isolated from Antarctic seawaters (Terra Nova Bay,
Ross Sea). Polar Research, 2004, 23 (2), 141-146.

[10] Watcharasing, S.; Angkathunyakul, P. and Chavadej, S.: Diesel oil removal from water by froth flotation under low interfacial tension and colloidal gas aphron conditions. Separation and Purification Technology, 2008, 62, 118-127.

[11] Wang, S.; Chu, L.; Chen, W.: Fouling-resistant composite membranes for separation of oil-in-water microemulsions. Chinese J. Chem. Eng., 2006, 14 (1), 37-45.

[12] Ademiluyi, F. T.; Amadi, S. A. and Amakama, N. J.: Adsorption and treatment of organic contaminants using activated carbon from waste Nigerian Bamboo. J. Appl. Sci. Environ. Manage., 2009, 13 (3), 39 - 47.

[13] Ayotamuno, M. J.; Kogbara, R. B.; Ogaji, S. O. T. and Probert, S. D.: Petroleum contaminated ground-water: Remediation using activated carbon. Applied Energy, 2006, 83 (11), 1258-1264.

[14] Okiel, K.; El-Sayed, M. and El-Kady, M. Y.: Treatment of oil-water emulsions by adsorption onto activated carbon, bentonite and deposited carbon. Egyptian Journal of Petroleum, 2011, 20, 9-15.

[15] Ahn, C. K.; Kim, Y. M.; Woo, S. H. and Park, J. M.: Removal of cadmium using acid-treated activated carbon in the presence of nonionic and/or anionic surfactants. Hydrometallurgy, 2009, 99, 209-213.

[16] Chen, J. P. and Wu, S.: Acid/base-treated activated carbons: characterization of functional groups and metal adsorptive properties. Langmuir, 2004, 20, 2233-2242.

[17] Amuda, O. S.; Giwa, A. A. and Bello, I. A.: Removal of heavy metal from industrial wastewater using modified activated coconut shell carbon. Biochem. Eng. J., 2007, 36, 174-181.

[18] Masooleh, M. S.; Bazgir, S.; Tamizifar, M. and Nemati, A.: Adsorption of petroleum hydrocarbons on organoclay. Journal of Applied Chemical Researches, 2010, 4 (14), 19-23.

[19] Moazed, H. and Viraraghavan, T.: Practice periodical of hazardous. Toxic and Radioactive Waste Management. 2005, $9(2), 130-134$ 
[20] Eren, E.; Cubuk, O.; Ciftci, H.; Eren, B. and Caglar, B.: Adsorption of basic dye from aqueous solutions by modified sepiolite: Equilibrium, kinetics and thermodynamics study. Desalination, 2010, 252 (1-3), 88-96.

[21] Bulut, E.; Ozacar, M. and Sengil, I. A.: Adsorption of malachite green onto bentonite: Equilibrium and kinetic studies and process design. Microporous and Mesoporous Materials, 2008, 115 (3), 234-246.

[22] Sears, G.: Determination of specific surface area of colloidal silica by titration with sodium hydroxide. Anal. Chem., 1956, 28, 1981-1983.
[23] Priyantha, N.; Senevirathna, C.; Gunathilake, P. and Weerasooriya, R.: Adsorption behavior of fluoride at normal brick (NB) - water interface. Int J Environ Protec Sci., 2009, $3,140-146$.

[24] Ashok, A.; Manas, B. and Anjali, P.: Removal of Crystal Violet dye from wastewater by surfactant modified alumina. Separation and Purification Technology, 2005, 44, 139-144.

[25] Sulaymon, A. H. and Kshash, J. M.: Removal of oil from wastewater by organoclay prepared from Iraqi bentonite. Journal of Engineering, 16 (4), 5778-5798, 2010. 